\title{
Serving his patients with passion and dedication-Obituary to Prof. Dr. Dr. h.c. Dietrich Niethammer
}

\author{
Peter Bader $^{1} \cdot$ Rupert Handgretinger ${ }^{2}$. Thomas Klingebiel ${ }^{3}$
}

Received: 7 February 2020 / Revised: 8 February 2020 / Accepted: 12 February 2020 / Published online: 24 February 2020

(c) Springer Nature Limited 2020

Prof. Niethammer was born on October 24, 1939 in Leipzig. He began his career as a pediatrician at the Ulm University Children's Hospital under the direction of Prof. Kleihauer. There, he was involved in the development of pediatric hematology and oncology. As early as 1975, he performed one of the first allogeneic bone marrow transplants in a child with severe aplastic anemia. In this respect, he is one of the pioneers of bone marrow and stem cell transplantation in pediatrics in Germany and Europe.

Dietrich Niethammer began his medical studies in Tübingen and continued in Vienna and Munich. He passed his state examination in Tübingen in 1966 and worked as an assistant doctor in hospitals in the Tübingen area. From 1969 to 1971 , he worked as a postdoctoral fellow in the biochemistry department at the Scripps Clinic in La Jolla, California. Back in Germany, he finished his pediatric education in Ulm. In 1977, he was awarded with the "habilitation" for pediatrics with the title "development of resistance to methotrexate and transport of folinic acid combinations," a topic which at that time was of great importance in view of the introduction of methotrexate in the treatment of malignant diseases. The habilitation is the highest-ranking university examination in German speaking and some Eastern European countries, with which the academic qualification (Latin: facultas docendi) is determined in a scientific subject as part of an academic

Peter Bader

Peter.bader@kgu.de

1 Department for Children and Adolescents Medicine, Division for Stem Cell Transplantation and Immunology, University Hospital Frankfurt, Goethe University, Frankfurt, Germany

2 Department for Hematology and Oncology, University Hospital for Children and Adolescents, University Hospital Tübingen, Tübingen, Germany

3 Department for Children and Adolescents Medicine, University Hospital Frankfurt, Goethe University, Frankfurt, Germany examination procedure which enables the candidates to be appointed as university professor.

Following this achievement, he was appointed to the professorship of the newly created department for pediatric hematology and oncology at the University Children's Hospital in Tübingen in 1978.

This was the time of rapid development in pediatric hematology and oncology and also the scientific society for pediatric oncology and hematology in Germany. From 1983 to 1985 , Dietrich Niethammer was deputy and from 1985 to 1989 chairman of the Society for Pediatric Oncology and Hematology in Germany.

During this time he was very committed to the psychosocial care of the children, founded the working group for psychosocial work and was its first speaker. In relation to politics and society, he addressed the need for professional psychosocial care for children with cancer and their families and consequently initiated a family-oriented program for the postclinical care of these children and their families.

Already in the early times of his career he realized the importance of bone marrow transplantation for children with malignant and nonmalignant diseases. Consequently, he established a competent stem cell transplant unit in Tübingen which soon was recognized in Germany and Europe. His spirit and his leadership enabled him to gather dedicated and eager fellows around him who together took part in the rapid development of this field. Out of his group many important implications started to rise: haploidentical transplantation, importance of chimerism, detection of minimal residual disease in the context of allogeneic SCT, and also early cellular immunotherapies were the focus of his team. Many of his fellows were awarded with professorships all over Germany. Moreover, his dedication also influenced many pediatricians in Europe and at the other side of the Atlantic.

Prof. Niethammer substantiated his idea that within the European Society for Bone Marrow Transplantation (EBMT) a specialized pediatric working group was necessary. Pediatricians, their ideas and results, and the special needs of their patients were not sufficiently represented in 
the EBMT's leukemia working group at that time. Based on his engagement, in 1995 the EBMT Pediatric Diseases Working Party was founded. Prof. Niethammer was elected as the first chairman and served in this position until 2002. The establishment of this working group showed the increasing self-confidence of the pediatric community and also the enabled important contributions from the pediatric transplant community within the EBMT. Prof. Niethammer served for the EBMT Society until his retirement in 2005. He was awarded with the Honorary Membership of our Society at the Annual Meeting in Lisbon in 2018. Regardless of his professional work, Dietrich Niethammer saw himself primarily as a pediatrician and felt responsible for the entire area of pediatrics. Consequently, after retiring, he assumed responsibility as general secretary of the German Academy for Pediatrics in Berlin.
As a fellow of the Wissenschaftskolleg in Berlin, he was able to devote himself to research and writing in 2005-2008 and put his experience from a long and intensive professional life and dealing with seriously ill and dying children in two well-regarded books: From an early age he had the experience that only dealing appropriately with the truth enables seriously ill children to find their silence and to maintain their dignity.

Dietrich Niethammer worked and fought on many borders for the interests of science, medicine, stem cell transplantation, and of course for pediatrics. He has influenced and mentored generations of doctors and researchers and he has become a role model for many of them in Germany, Europe, and beyond.

Dietrich Niethammer died on February 3rd in 2020 in Tübingen, Germany. 